\title{
TORTIKOLIS MUSKULAR KONGENITAL
}

\author{
Imelda E. Kawatu \\ Engeline Angliadi \\ Bagian/SMF Ilmu Kedokteran Fisik dan Rehabilitasi \\ Fakultas Kedokteran Universitas Sam Ratulangi Manado \\ Email: imeldakawatu@yahoo.com
}

\begin{abstract}
Torticollis, or wryneck, is a group of symptoms based on many causes that clinically manifests itself as a crooked or rotated neck. Congenital muscular torticollis is the most common type of congenital torticolllis which occurs in four per 1000 births and one per 300 live births with $75 \%$ of these cases on the right side. It was found that $90.1 \%$ of plagiocephalic cases incured this torticollis. In this condition, due to contractions of the neck muscles, the head turns and tilts to one side, meanwhile the chin points to the opposite side. Congenital muscular torticollis is caused by a shortening of the sternocleidomastoid muscle due to trauma during labour or abnormal fetal position in utero. Signs and symtoms of congenital muscular torticollis are recognized as early as two months after birth in which the head turns to one side associated with neck muscle hypertrophy, muscle spasm, and a limited range of motion (ROM). The management of congenital muscular torticollis consists of pharmacological, non-pharmacological, and surgical treatments. The prognosis is stated as good if there is a good improvement after 6 months of rehabilitation, but it is stated bad if there is no improvement after 6 months of treatment with a continuation of the asymetrical face.
\end{abstract}

Keywords: congenital muscular torticollis, management

\begin{abstract}
Abstrak: Tortikolis adalah kekakuan leher yang menimbulkan spasme otot yang secara klinis bermanifestasi sebagai leher yang bengkok atau terputar. Tortikolis bukan merupakan suatu diagnosis melainkan kumpulan gejala dengan berbagai gangguan yang mendasarinya. Tortikolis muskular kongenital ialah bentuk yang paling umum dari tortikolis kongenital dengan insiden sekitar 4 per 1000 kelahiran, dan 1 dari setiap 300 kelahiran hidup. Pada tortikolis muskular kongenital terjadi kontraksi otot-otot leher (75\% terbanyak pada sisi kanan) yang menyebabkan posisi kepala turn dan tilt ke satu sisi dan dagu mengarah ke sisi yang berlawanan. Penyebab terjadinya tortikolis muskular kongenital ialah pemendekan otot sternokleidomastoid akibat trauma selama proses persalinan, atau posisi bayi dalam kandungan. Umumnya, gejala dan tanda klinis diketahui pada 2 bulan pertama dimana kepala mengarah ke arah sisi sakit, pembesaran otot-otot leher, spasme otot, dan keterbatasan lingkup gerak sendi leher. Penanganan tortikolis muskular kongenital terdiri dari farmakologis, nonfarmakologis, dan pembedahan. Prognosis disebut baik bila tercapai hasil yang baik setelah 6 bulan terapi dengan penanganan rehabilitasi, dan memburuk bila tidak terdapat perubahan dalam 6 bulan terapi ditandai oleh wajah yang asimetris.
\end{abstract}

Kata kunci: tortikolis muskular kongenital, penanganan

Tortikolis berasal dari bahasa Latin, torus berarti bengkok, dan collum berarti leher. Pada tortikolis terjadi kekakuan leher yang menimbulkan spasme otot yang secara klinis bermanifestasi sebagai leher yang bengkok atau terputar. ${ }^{1,2}$ Tortikolis bukan merupakan suatu diagnosis melainkan kumpulan gejala dengan berbagai 
gangguan yang mendasarinya.

Tortikolis dapat diklasifikasikan menjadi tortikolis kongenital, tortikolis didapat, dan tortikolis spasmodik. Bayi dengan kemiringan kepala ke satu sisi dikategorikan sebagai tortikolis kongenital. Kekakuan pada anak sampai dewasa biasanya dikenal sebagai tortikolis didapat, sedangkan gerakan spasmodik yang intermiten pada otot-otot leher sampai ke wajah merupakan tortikolis spasmodik. ${ }^{3}$

Tortikolis muskular kongenital merupakan bentuk yang paling umum dari tortikolis kongenital $^{1}$ dengan insiden diperkirakan 4 per 1000 kelahiran, ${ }^{4}$ dan 1 dari setiap 300 kelahiran hidup. ${ }^{2}$ Cheng et al. $^{5}$ melaporkan bahwa insiden tortikolis kongenital bervariasi dari 0,3-1,9\%. Tortikolis muskular kongenital lebih banyak ditemukan pada anak perempuan dibandingkan laki-laki, ${ }^{6}$ dan terbanyak terdapat pada sisi sebelah kanan (75\%). ${ }^{4}$

\section{DEFINISI}

Tortikolis (wryneck) adalah suatu kondisi di mana kepala berada pada posisi miring, 3,7,8-11 dengan dagu menunjuk ke salah satu bahu, sedangkan kepala miring ke arah bahu yang berlawanan; ${ }^{8-11}$ juga disebut rotasi leher. ${ }^{12}$ Tortikolis muskular kongenital adalah keadaan dimana terjadi kontraksi otot-otot leher yang menyebabkan kepala turn and tilt ke satu sisi dan dagu mengarah ke sisi yang berlawanan, yang didapat sejak lahir. Menurut Freed dan Collen, deformitas postural yang terdeteksi saat kelahiran atau segera setelah lahir terjadi akibat pemendekan dan fibrosis dari salah satu otot sternokleidomastoid. ${ }^{2}$

Secara anatomi, otot sternokleidomastoid terletak sangat superfisial pada samping kiri kanan leher bagian depan. Kedua otot ini akan terlihat berkontraksi bersamaan pada posisi terlentang dengan mengangkat kepala ke atas. Untuk mengetahui gangguan satu sisi, dapat diberikan tahanan pada saat mengadakan gerakan memutar kepala. Otot ini akan berfungsi sebagai fleksor kepala bila bekerja serentak, dan sebagai lateral fleksor dan rotator bila bekerja satu sisi. ${ }^{7}$

\section{ETIOLOGI DAN PATOFISIOLOGI}

Penyebab tersering terjadinya tortikolis muskular kongenital ialah gangguan pada otot sternokleidomastoid. ${ }^{2}$ Pada anak, penyebab terjadinya tortikolis secara umum dibagi atas tipe oseus, non-oseus dan neurogenik. ${ }^{2,3}$

Tipe osseus disebabkan oleh disfungsi osipitoservikal, ${ }^{2,3}$ disfungsi vertebra servikal (sindrom Klippel-Feil), ${ }^{13,14}$ dan hemivertebra. $^{2,3}$ Pada sindrom Klippel-Feil terdapat fusi dan berkurangnya jumlah vertebra servikal C1-C2 yang menyebabkan leher menjadi pendek, garis rambut rendah, dan terbatasnya gerakan leher. ${ }^{13,14}$ Selain itu, dapat terjadi skoliosis kongenital, dan biasanya dihubungkan dengan kelainan kongenital lainnya. ${ }^{7}$ Tipe nonosseus merupakan tortikolis muskular kongenital. ${ }^{1,2}$

Tipe neurogenik disebabkan oleh tumor susunan saraf pusat, sindrom Sandifer (kondisi yang menyebabkan refluks gastrointestinal), malformasi Arnold Chiari, tortilokis okular, dan tortikolis paroksismal. ${ }^{3,14,15}$ Pada malformasi Arnold Chiari, tonjolan medula oblongata dan serebelum menjulur lewat foramen magnum dan memasuki kanalis spinalis servikal, kadang-kadang disertai spina bifida. Fiksasi medula spinalis bagian bawah atau radiks sarafnya yang terjadi selama kehidupan in utero telah menimbulkan tarikan pada medula spinalis bagian atas dan batang otak sehingga medula oblongata dan serebelum mengalami herniasi lewat foramen magnum. Malformasi ini biasanya disertai hidrosefalus yang berhubungan dengan obstruksi sisterna basalis. Keluhan dan gejala malformasi Arnold-Chiari ini biasanya tampak pada minggu-minggu pertama kehidupan dan berhubungan dengan hidrosefalus serta efek pertumbuhan saraf lainnya. Prognosis pada kasus malformasi ini buruk. Kompresi pada batang otak dan teregangnya saraf kranialis serta servikal dapat menyebabkan tortikolis. ${ }^{14}$ Tortikolis okular yaitu terjadi paresis pada otot oblik superior, ${ }^{3}$ sedangkan tortikolis paroksismal 
yaitu pergerakan saraf secara periodik. ${ }^{14}$

Patofisiologi dan penyebab pemendekan pada salah satu otot sternokleidomastoid yang mengakibatkan tortikolis muskular kongenital tidak diketahui. ${ }^{2,7}$ Teori utama penyebab pemendekan otot sternokleidomastoid ialah trauma in utero, trauma otot selama proses persalinan, kompresi jaringan lunak yang menyebabkan sindrom kompartemen, dan abnormalitas kongenital pada jaringan lunak dalam otot sternokleidomastoid. $^{2}$ Menurut Hammer, ${ }^{16}$ terjadinya tortikolis muskular kongenital akibat fetus in utero dengan posisi sungsang, dan saat persalinan akibat tarikan dalam persalinan sungsang dimana terjadi trauma otot sternokleidomastoid yang teregang saat melahirkan kepala, sehingga otot ini tidak tumbuh pada satu sisi/hipertrofi pada sisi sebelah, ${ }^{13}$ atau dapat terjadi robekan pada otot leher akibat tarikan pada proses persalinan sehingga terbentuk fibrosis (kondisi ini tidak selalu ditemukan). ${ }^{1,2,12}$

\section{GAMBARAN KLINIS}

Tortikolis muskular kongenital biasanya mulai terlihat pada usia 2-4 minggu atau bisa lebih lambat yaitu 6-8 minggu dan berkembang sesuai usia anak yang cenderung menahan posisi kepala miring ke satu sisi. ${ }^{1}$ Mac Donald (1969) mengklasifikasikan tortikolis muskular kongenital atas 3 sub-kelompok klinis, yaitu: 1) kelompok tumor sternomastoid dengan massa yang jelas terlihat, $(42,7 \%) ; 2$ ) kelompok tortikolis muskular dengan pemendekan otot sternokleidomastoid (30,6\%); dan 3) kelompok tortikolis postural yaitu tortikolis tanpa adanya pemendekan otot atau tumor $(22,1 \%) .{ }^{1,2,5}$

Gejala dan tanda awalnya biasanya diketahui pada usia 2 bulan pertama, berupa: turn dan tilt kepala ke arah sisi sakit ( $75 \%$ mengenai sisi kanan); pembesaran otot-otot leher yang kemungkinan telah ada sejak lahir; spasme otot-otot leher dan punggung atas; keterbatasan lingkup gerak sendi leher; dan bisa ditemukan adanya benjolan/tumor di leher yang disebut fibromatosis colli. ${ }^{2,9,13}$

Tortikolis muskular kongenital bisa ditemukan ringan sampai berat. Umumnya tortikolis ini berkembang secara progresif lambat dalam 1-5 tahun, kemudian menetap seumur hidup sehingga menyebabkan gerakan kepala dan leher terbatas yang dapat memengaruhi postur. ${ }^{2,6}$

\section{PEMERIKSAAN PADA TORTIKOLIS MUSKULAR KONGENITAL}

Pada pemeriksaan awal biasanya teraba massa/tumor di daerah leher dengan konsistensi lunak, tidak nyeri bila ditekan, yang berangsur-angsur menghilang pada 46 bulan kemudian. Terjadinya tortikolis kongenital dapat dikaitkan dengan hipdysplasia (10-20\%). Pemeriksaan awal mencakup riwayat persalinan dan pemeriksaan fisik untuk menilai apakah lesi asal kongenital atau didapat, dan akibat trauma atau non-trauma saat kelahiran. ${ }^{2,5}$

Pemeriksaan fisik ditujukan untuk menentukan adanya keterbatasan lingkup gerak sendi (LGS) leher. Penilaian ini dilakukan dengan menggunakan artrodial protaktor pada bayi atau anak dalam posisi terlentang. Pemeriksaan untuk menilai keterbatasan gerakan pada leher dilakukan dengan cara: posisi bahu seimbang, kepala dan leher disokong, dan kepala digerakkan ke arah berlawanan. Protaktor diletakkan di leher, lalu dilihat gerakan kepala yang terbatas pada derajat yang mana. ${ }^{5}$

Cheng et al. telah mengembangkan suatu skala penilaian yang bermanfaat dalam menentukan keberhasilan pengobatan pada anak-anak dengan tortikolis muskular kongenital (Tabel 1). Pengobatan konservatif dinilai ‘baik' sekitar 91,1\% dari 1086 anak-anak di Cina sehingga disebut 'skala Cheng'. ${ }^{9}$ Kriteria penilaian (skoring) dilakukan dengan menggunakan points, yaitu: 16-18 points dinilai baik sekali, 1215 points baik, 6-11 points kurang baik, dan $<6$ points jelek. ${ }^{5}$ 
Tabel 1. Skala Cheng ${ }^{5}$

\begin{tabular}{|c|c|c|c|c|c|}
\hline \multirow[b]{2}{*}{ Category } & \multicolumn{5}{|c|}{ Scoring Criteria } \\
\hline & 3 Points & 2 Points & 1 Point & 0 Points & $\begin{array}{c}\text { Points } \\
\text { awarded }\end{array}$ \\
\hline Rotation deficit (degrees)* & $<5$ & $6-10$ & $11-15$ & $>15$ & \\
\hline $\begin{array}{l}\text { Lateral bending deficit } \\
\text { (degrees)* }\end{array}$ & $<5$ & $6-10$ & $11-15$ & $>15$ & \\
\hline Craniofacial asymetry & None & Mild & Moderate & Severe & \\
\hline Residual band & None & Lateral & Lateral/cleidal & Cleidal/sternal & \\
\hline Head tilt & None & Mild & Moderate & Severe & \\
\hline $\begin{array}{l}\text { Subjective assessment by } \\
\text { parents } \\
\text { (cosmetic and functional) }\end{array}$ & Excellent & Good & Fair & Poor & \\
\hline
\end{tabular}

Modified from Cheng et al. ${ }^{5}$ Adapted with permission from $J$ Bone Joint Surg.

Outcome rating determined by total score: excellent $=16-18$ pts; good $=12-15$ pts; fair $=6-11$ pts; poor $=<6$ pts

*Measured with arthrodial goniometer; deficit determined by comparison to contralateral side

Menurut Turek, pada setiap kasus tortikolis harus dilakukan minimal pemeriksaan radiologik sebelum menegakkan diagnosis, yang terdiri dari foto polos servikal untuk menilai adanya abnormalitas tulang servikal; ${ }^{16}$ dan MRI atau CT-scan bila ada plagiocephaly, (pendataran kepala pada satu sisi) untuk mengetahui adanya penutupan tulang tengkorak yang terlalu cepat (prematur). ${ }^{3,13}$ Plagiocephaly ditemukan pada $90,1 \%$ anak dengan tortikolis muskular kongenital. ${ }^{13}$

Tortikolis bisa mengakibatkan kelainan perkembangan bentuk dasar tengkorak atau wajah. ${ }^{17}$ Pada plagiocephaly dan tortikolis yang terjadi sejak neonatus, terdapat pembatasan ruang gerak in utero yang menyebabkan kompresi asimetris pada tulang tengkorak secara terus-menerus dan pemendekan salah satu otot sternokleidomastoid sampai akhir masa kehamilan.,18 Tortikolis muskular kongenital juga dapat menyebabkan plagiocephaly setelah lahir akibat penekanan sesisi pada dasar tengkorak saat bayi tersebut tidur terlentang. Menurut Freed dan Colleen ${ }^{2}$ bayi dengan deformitas plagiocephaly mempunyai gerakan otot-otot servikal yang terbatas.

\section{DIAGNOSIS TORTIKOLIS MUSKU- LAR KONGENITAL}

Diagnosis tortikolis biasanya ditegakkan oleh dokter ahli anak pada usia 2-3 bulan ketika terdapat pseudotumor pada otot sternokleidomastoid, posisi kepala yang abnormal, keterbatasan gerakan pada servikal, atau plagiocephaly. Rerata usia untuk menegakkan diagnosis tortikolis yang dilaporkan ialah 24 hari pertama,1 bulan, dan 4 bulan. Pada pemeriksaan radiologik foto polos kepala terdapat abnormalitas tulang servikal. ${ }^{2}$

\section{DIAGNOSIS BANDING TORTIKOLIS MUSKULAR KONGENITAL}

Tortikolis muskular kongenital bukan merupakan satu-satunya penyebab terjadinya tortikolis. Pada 1 dari 5 anak dengan tortikolis muskular kongenital, penyebabnya ialah keterlibatan jaringan lunak atau tulang. Diagnosis banding tortikolis muskular kongenital ialah tortikolis didapat, sindrom Klippel-Feil, dan atlanto aksial rotator subluksasi., ${ }^{9,14}$

Pada tortikolis didapat terjadi kekakuan dan nyeri pada satu atau lebih otot seperti otot sternokleidomastoid dan otot trapesius yang berlangsung selama 1-4 minggu, kadang-kadang disertai pilek atau postur tubuh yang lemah. Akibat infeksi farings posterior dan iritasi saraf sampai ke otot leher terjadi tortikolis yang dapat diobati dengan pemberian antibiotic, dan jika bertambah parah dengan tindakan pembedahan berupa debridement. ${ }^{9,14}$ 
Sindrom Klippel-Feil yaitu suatu kelainan kongenital dimana terdapat fusi dan berkurangnya jumlah tulang servikal sehingga leher menjadi pendek, garis rambut rendah, dan terbatasnya gerakan leher. Insiden sindrom ini 0,2 per 1000 kelahiran dengan penyebab yang tidak diketahui. Sindrom ini dapat disertai anomali pertumbuhan medula spinalis servikal seperti: syringomyelia, spina bifida, dan defek kongenital lainnya. ${ }^{14}$

Atlanto aksial rotator subluksasi yaitu trauma pada leher dimana posisi dua vertebra berdekatan pada tulang tengkorak sehingga terjadi robekan ligamen. Diagnosis ditegakkan berdasarkan perlangsungan yang akut, nyeri, dan deformitas leher akibat adanya spasme otot (anak selalu memegang kepala dengan tangannya). Penanganan atlanto aksial rotator subluksasi dengan traksi servikal untuk subluksasi kemudian disokong pada ligamen yang cedera dengan casting atau bracing. ${ }^{14}$

\section{PENANGANAN TORTIKOLIS MUSKULAR KONGENITAL}

Pada keterbatasan rotasi leher, pemeriksaan diawali dengan $\mathrm{X}$-ray vertevra servikal sedangkan penyebab tortikolis didapat dari anamnesis. ${ }^{2}$ Penanganan tortikolis muskular kongenital terdiri atas non-farmakologis (rehabilitasi medik), farmakologis, dan pembedahan. ${ }^{2}$

Penanganan rehabilitasi medik meliputi fisioterapi, terapi okupasi, ortotik prostetik, psikologis, dan edukasi di rumah oleh petugas sosial. Penanganan rehabilitasi medik bertujuan untuk mencegah memburuknya gejala tortikolis muskular kongenital. Tujuan umum jangka panjang yaitu restorasi kosmetik dari mobilitas leher, meminimalkan terjadinya deformitas anomali kraniofasial, dan mencegah terjadinya skoliosis servikal. Untuk mencapai keberhasilan dalam tujuan rehabilitasi yang efektif dan efisien diperlukan tim rehabilitasi medik yang terdiri dari: dokter, fisioterapis, terapis okupasi, ortotik prostetik, pekerja sosial medik, psikolog, dan perawat rehabilitasi medik. $^{19}$

Fisioterapi terdiri dari program terapi latihan untuk mengoreksi tortikolis muskular kongenital pada bayi berusia $<1$ tahun. Program yang diberikan terdiri dari: positioning yaitu menjauhkan sendi sternoklavikular dari prosesus mastoideus; peningkatan LGS secara lembut; ${ }^{1}$ dan latihan peregangan, dengan cara meregangkan (lateral bending) leher menjauhi sisi tortikolis dan secara pelan-pelan merotasikan kepala dan wajah ke sisi tortikolis. Posisi ini dipertahankan selama 5 detik (6 hitungan) dan diulang 10-15 kali, dilakukan 4-6 kali per hari atau lebih baik bila dilakukan setiap kali ganti popok, serta diberikan masase sebelum peregangan untuk relaksasi. ${ }^{1,19}$ Tujuan pengelolaan fisioterapi pada bayi dengan tortikolis muskular kongenital meliputi: peningkatan LGS yang dilakukan secara aktif dan pasif, disesuaikan dengan usia; pencegahan terjadinya kontraktur atau terbatasnya gerakan pada bayi yang dapat terbentuk akibat fibrosis pada otot sternokleidomastoid; memposisikan wajah, kepala dan leher, dengan fiksasi ke arah simetris; dan pengembangan reaksi postural ke segala arah. ${ }^{1}$

Pada terapi okupasi, terapis melakukan latihan dengan aktivitas permainan pada bayi/ anak dengan posisi saat tidur, duduk, menggendong, atau berbalik, minum susu, atau makan. Penatalaksanaannya dengan cara meletakkan mainan di depan bayi/anak. Pada posisi telungkup dimulai dengan 1-2 menit kemudian ditingkatkan. Pada awalnya bayi/anak akan menangis dan menolak posisi tersebut. Penekanan pada perut akan meningkatkan kekuatan otot perut dan kepala, serta mencegah terjadinya pendataran kepala. Bayi/anak pada posisi miring harus sejajar tatapan dengan terapis. Pada saat melakukan latihan dengan aktifitas permainan, posisi kepala antara bayi/anak dan terapis saling berhadapan. ${ }^{20}$

Mengenai ortotik prostetik, banyak anak tortikolis mempunyai deformitas plagiocephaly yang cukup berat sehingga diharuskan untuk pemakaian ortosis sebagai penopang pembentukan tulang kranial. Anak-anak tortikolis dengan plagiocephaly 
memerlukan pemakaian ortosis yang lama dalam pembentukan tulang tengkorak karena adanya keterbatasan gerakan pada servikal. ${ }^{1,2,18,20}$ Ortosis servikal digunakan sebagai salah satu alat bantu untuk mengoreksi posisi kepala. Ortosis yang sering digunakan berupa collar pada anak, disesuaikan dengan usia. Pada bayi yang berusia kurang dari 4 bulan, dapat berupa penopang atau bantalan yang disebut cervical collar. ${ }^{19,20}$ Pada bayi/anak berusia lebih dari 4 bulan digunakan tubular orthosis for torticollis collar (TOT collar) yang disesuaikan untuk menopang leher pada sisi gangguan agar kembali ke posisi netral. ${ }^{21}$

Penanganan psikologis ditujukan untuk memberikan dorongan psikologis pada orangtua berupa motivasi melakukan latihan seperti yang dilakukan oleh para terapis, dan dukungan mental bagi orangtua yang mengalami kecemasan. ${ }^{22}$

Petugas sosial medik bertanggung jawab dalam menentukan keberhasilan pelaksanaan program latihan. Program edukasi di rumah harus dimasukkan dalam rutinitas keluarga, seperti cara memberi makan, memberi susu, menggendong, dan posisi tidur. Kepatuhan orang tua menentukan keberhasilan terapi. ${ }^{23}$

Penanganan farmakologis yaitu pemberian injeksi toksin botulinum (Botox) yang dapat meningkatkan efektivitas peregangan pada sisi yang kontraktur dan penguatan otot-otot yang sehat. ${ }^{2}$

Pembedahan diindikasikan bila gejala menetap setelah usia 1 tahun meskipun sementara mendapat pengobatan konservatif. Sebuah kriteria alternatif dilaporkan untuk intervensi bedah ialah berkurangnya residu dalam rentang rotasi lebih besar dari $15^{0}$ setelah 6 bulan latihan terkontrol. ${ }^{2}$ Tindakan pembedahan terdiri dari metode tenotomy dan dilanjutkan dengan Zlengthening pasca operasi. ${ }^{2,8,24}$.

\section{PROGNOSIS TORTIKOLIS MUSKU- LAR KONGENITAL}

Sebagian besar kasus memberikan hasil yang baik setelah 6 bulan diberi terapi rehabilitasi, dengan waktu pengobatan yang berbeda-beda. Penanganan tim rehabilitasi diharapkan menghasilkan gerakan penuh dan posisi kepala yang lebih baik ke arah simetris. $^{7}$ Hasil penanganan dikatakan sempurna bila mencapai $90 \%$ dan koreksi permanen tortikolis pada anak-anak yang mendapat stretching setiap hari; dan hanya $10 \%$ yang memerlukan pembedahan. Prognosis dikatakan buruk bila kepala anak secara terus menerus miring ke satu sisi, yang berakibat terbentuk wajah asimetris yang dapat menyebabkan perbedaan pada mata dan telinga; hal ini merupakan masalah yang memperburuk pertumbuhan anak kelak. ${ }^{7}$

\section{SIMPULAN}

Tortikolis muskular kongenital adalah keadaan dimana terjadi kontraksi otot-otot leher yang menyebabkan kepala 'turn dan tilt' ke satu sisi dan dagu mengarah ke sisi yang berlawanan. Penyebabnya ialah pemendekan otot sternokleidomastoid akibat trauma selama proses persalinan, serta posisi bayi dalam kandungan.

Penanganan terdiri dari farmakologis, non-farmakologis, dan pembedahan. Prognosis dikatakan baik bila tercapai hasil yang baik setelah 6 bulan terapi dengan penanganan rehabilitasi, dan dikatakan memburuk bila tidak terdapat perubahan dalam 6 bulan terapi disertai wajah yang asimetris.

\section{DAFTAR PUSTAKA}

1. Macias CG, Gan V. Congenital Muscular Torticollis. Philips W, Torchia MM, editors. UpToDate Wolter Kluwer Health. [homepage on the Internet]. 2013 [updated 2013 May 20; cited 2013 Nov 09]. Available from: http://www.uptodate.com/ contents/congenital-muscular-torticollis? source=see_link.

2. Freed SS, Colleen CB. Identification and treatment of congenital muscular torticollis in infants. JPO [serial online]. 2004 [cited 2013 Nov 09]; 16(4S):18. Available from: http://www.oandp.org/jpo/library/200404S 018.asp.

3. Barackman H. Torticollis [homepage on 
the Internet]. Nodate [cited 2013 Nov 09]. Available from: http://morphopedics. wikidot.com/torticollis.

4. Diamond M, Armento M. Children with disabilities. In: Delisa JA, editor. Physical Medicine and Rehabilitation Principles and Practice. Philadelphia: Lippincott Williams \& Wilkins, 2005; p. 1514.

5. Cheng JC, Tang SP, Chen TM, Wong MW, Wong EM. The clinical presentation and outcome of treatment of congenital muscular torticollis in infants. A study of 1,086 cases. J Pediatr Surg. 2000; 35(7):1091-6.

6. Joshi J, Kotwal P, editors. Essentials of Orthopaedics and Applied Physiotherapy. New Delhi: B.I. Churchill LivingStone; 1999.

7. Rossi R, Alexander M, Cuccurullo S. Pediatric rehabilitation. In: Cuccurullo S, editor. Physical Medicine and Rehabilitation Board Review. New York: Demos, 2004; p. 661.

8. Burstein FD, Cohen SR. Endoscopic surgical treatment for congenital muscular torticollis. Plast Reconstr Surg. 1998;101(1):20-4.

9. Spiegel DA, Hosalkar HS, Dormans JP, Drommond DS. The neck. In: Kliegman RM, Behrman RE, Jenson HB, Stanton BF, editors. Nelson Textbook of Pediatrics (Eighteenth Edition). Philadelphia, Saunders Elsevier, 2007; p. 679.

10. Persing J, James $H$, Swanson J, Kattwinkel J. Prevention and management of positional skull deformities in infants. Pediatrics. 2003;112(1):199-202.

11. Patel M, Shah K. Orthopedics. In: Rakel RE, editor. Textbook of Family Medicine (Seventh Edition). Philadelphia: Saunders Elsevier, 2007; p. 42.

12. Orthopedic \& sport physical therapy associates, Inc. OSPTA@home and valley outpatient rehabilitation. Congenital muscular torticollis [serial online]. 2010 [cited 2010 vol14]; 14(55): Available from: http://www.osptainc.com/News letters/Other/Congenital\%20Muscular.pdf

13. Do TT. Congenital muscular torticollis: current concepts and review of treatment. Curr Opin Pediatr. 2006;18(1):26-9.

14. Chusid JG. Defek Kongenital dalam Neuroanatomi Korelatif dan Neurologi Fungsional Bagian Dua. Hartono A, penerjemah. Yogyakarta: Gajahmada
University Press, 1993; p. 525.

15. Shaw L. Torticollis and Sandifer's syndrome [homepage on the Internet]. Nodate [cited 2013 Oct 11]. Available from: http://www.pollywogbaby.com/ torticollis-sandifers-syndrome.html.

16. Hammer W. Congenital muscular torticollis. Dynamic Chiropractic. [serial online]. 2003 [cited 2013 Oct 11];21(9). Available from: http://www.dynamicchiro practic.com

17. Solomon L, Warwick D, Nayagam S, editors. Deformities of the neck. In: Children in Apley's System of Orthopaedics and Fractures (Eight Edition). London: Arnold Hodder, 2001.; p. 360-1.

18. Ennis B, Placzek JD. Pediatric orthopaedic physical therapy. In: Placzek JD, Boyce DA, editors. Orthopaedic Physical Therapy Secrets (Second Edition). Philadelphia, PA, USA: Mosby Elsevier, 2006; p. 223-230.

19. Cottrill-Mosterman S, Jacques C, Bartlett O, Beauchamp R, Devlin B. Orthotic treatment of head tilt in children with congenital muscular torticollis. J Assoc Child Prosthet Orthot Clin. 1987;22(1):1.

20. Jacques C, Karmel-Ross $\mathbf{K}$. The use of splinting in conservative and postoperative treatment of congenital muscular torticollis. In: Karmel-Ross $\mathrm{K}$, editor. Torticollis Differential Diagnosis, Assessment and Treatment, Surgical Management and Bracing. Binghamton, NY: Haworth Press, Inc, 1997; p. 81-90.

21. Symmetric designs. The TOT Collar ${ }^{\mathrm{TM}}$ [homepage on the Internet]. Nodate [cited 2013 Oct 11]. Available from: http://www.symmetric-designs.com.

22. Pratikno W. Problem emosional dan cara mengatasinya. In: Hamid T. Kumpulan Naskah Kursus Terapi Okupasi. Semarang: Unit Rehabilitasi Medik FK UNDIP, 1992; p. 17-9.

23. Waspodo D. Peranan pekerja sosial medik dalam deteksi dini cacat. In: Hamid $\mathrm{T}$. Kumpulan Naskah Kursus Terapi Okupasi. Semarang: Unit Rehabilitasi Medik FK UNDIP, 1992; p. 22-4.

24. Cheng CY, HO KW, Leung KK. Multiadjustable post-operative orthosis for congenital muscular torticollis. Prosthetic orthotic service, Prince of Wales Hospital, Hongkong. 1993;17(1):115-119. 